\title{
Echocardiographic Parameters as Cardiovascular Mortality Predictors in Chronic Hemodialysis Patients
}

\author{
Misato Koeda ${ }^{1}$, Tetsuya Ogawa ${ }^{2}$, Kyoko Ito ${ }^{3}$, Takaaki Tsutsui ${ }^{3}$, Kosaku Nitta ${ }^{{ }^{*}}$ \\ ${ }^{1}$ Department of Medicine, Kidney Center, Tokyo Women's Medical University, Tokyo, Japan \\ ${ }^{2}$ Department of Medicine, Medical Center East, Tokyo Women's Medical University, Tokyo, Japan \\ ${ }^{3}$ Department of Nephrology, Hidaka Hospital, Gunma, Japan \\ Email: ${ }^{*}$ knitta@kc.twmu.ac.jp
}

Received 20 April 2014; revised 15 May 2014; accepted 6 June 2014

Copyright (C) 2014 by authors and Scientific Research Publishing Inc.

This work is licensed under the Creative Commons Attribution International License (CC BY).

http://creativecommons.org/licenses/by/4.0/

c) (†) Open Access

\begin{abstract}
Background: Hemodialysis (HD) patients have high rates of cardiovascular (CV) mortality. Although structural and functional echocardiographic alterations in HD patients have been the subject of several survival analysis studies, the prognostic value of these alterations is not well established. The aim of this study was to determine the prognostic value of echocardiographic parameters in chronic HD patients. Objectives: One hundred eighteen HD patients were clinically evaluated and underwent Doppler echocardiography, being followed for $45.7 \pm 13.6$ months. The outcome measures were CV mortality. The predictive value of echocardiographic variables was evaluated by Cox regression model and survival curves were constructed using the Kaplan-Meier method and log-rank test to compare them. Results: CV diseases accounted for $46.4 \%$ of all deaths during the follow-up period. We found that the event-free survival rates in one and two years were $\mathbf{9 6 . 5 \%}$ and $83.0 \%$, respectively. Diabetes and $\mathrm{E} / \mathrm{e}^{\prime}$ ratio were predictors of $\mathrm{CV}$ outcome by multivariate analyses. Conclusion: Diabetes and diastolic dysfunction are independent predictors of $\mathrm{CV}$ mortality in chronic HD patients.
\end{abstract}

\section{Keywords}

Diastolic Dysfunction, Echocardiography, Hemodialysis, Cardiovascular Mortality, Prognosis

\section{Introduction}

The annual mortality rates in hemodialysis (HD) patients are high. According to the dialysis census of the USA,

"Corresponding author.

How to cite this paper: Koeda, M., Ogawa, T., Ito, K., Tsutsui, T. and Nitta, K. (2014) Echocardiographic Parameters as Cardiovascular Mortality Predictors in Chronic Hemodialysis Patients. International Journal of Clinical Medicine, 5, 635-643. 
the survival of HD patients in the country was $77.4 \%$ in one year and 34.2\% in five years, from 1999 to 2003 [1]. In Japan, the annual crude mortality was $10.2 \%$ in 2011[2].

Cardiovascular (CV) diseases account for approximately 40\% - 50\% of all deaths in HD patients. Moreover, these patients are often hospitalized and CV diseases account for approximately one third of hospital admissions [3].

Structural and functional alterations detected by echocardiography, such as left ventricular (LV) hypertrophy and systolic and diastolic dysfunction, are very prevalent in the HD population. Doppler echocardiographic diagnosis of these abnormalities has been an important step for the characterization of individuals with higher CV risk [4] [5].

Several studies have reported to determine the prognostic value of alterations such as LV hypertrophy and systolic dysfunction in HD patients [6]-[8]. However, studies evaluating the predictive value of diastolic dysfunction in this population are scarce. Thus, the objective of this study was to determine the prognostic value of echocardiographic parameters in chronic HD patients.

\section{Methods}

\subsection{Study Design and Population}

This is an observational and prospective cohort study. The subjects of this study were 118 maintenance HD patients (83 men and 35 women) treated in the Dialysis Unit of Hidaka Hospital (Gunma, Japan). Each patient underwent HD three times weekly (4 hours/day). Blood pressures (BP) were measured with a mercury sphygmomanometer with the patient in the supine position after 10 to 15 minutes of rest, and mean values for 1 month at enrollment were used for the analysis. This study was in compliance with the Declaration of Helsinki and was approved by the Institutional Review Board of Hidaka Hospital. All subjects gave their informed consent.

Inclusion criteria were patients aged 20 years and older, undergoing HD therapy for at least three months. All patients in this study had no history of previous CV diseases. Exclusion criteria were: recent history (less than six months) of acute myocardial infarction, percutaneous or surgical revascularization, unstable angina or cerebrovascular accident, decompensated congestive heart failure; severe valvular disease; pulmonary hypertension, BP > 160/110 mmHg, uncontrolled atrial fibrillation or complex ventricular arrhythmia, uncontrolled blood sugar levels, malignancies, active infection; irregular dialysis regimen; incapacity to obtain informed consent from the patient and inadequate echocardiographic window.

Patients were clinically evaluated and underwent a Doppler echocardiography during the period from March to December 2007, with an interval $<30$ days between the two procedures. Subsequently, they were followed regularly until December 2013 or until the occurrence of outcome.

\subsection{Doppler Echocardiogram}

The echocardiograms were performed on echocardiography equipment, an Aplio XV (TOSHIBA, Tokyo, Japan) ultrasound imager equipped with a 2.2/4.4 MHz (harmonics) phased-array 3S transducer during continuous electrocardiographic recording as previously described [9]. The examinations were performed in the interdialytic period, within 24 hours after the dialysis session by a single medical professional, trained and skilled in echocardiography, with patients at rest and in left lateral decubitus position. Echocardiographic measurements followed the recommendations of the American Society of Echocardiography [10]-[12] and, for each variable, at least three cycles were analyzed.

The assessment of LV geometry was obtained by two-dimensional image, with the following variables: left ventricular end-diastolic diameter of (LVDD) and left ventricular end-systolic diameter (LVDS). The left ventricular mass (LVM) was calculated using the formula proposed by Devereux et al. [13] and then indexed to body surface area (BSA), to obtain the left ventricular mass index (LVMI = LVM/BSA). LV hypertrophy (LVH) was diagnosed when LVMI was $>115 \mathrm{~g} / \mathrm{m}^{2}$ for men and $>95 \mathrm{~g} / \mathrm{m}^{2}$ for women. The left ventricular ejection fraction (LVEF) was calculated by the method described by Teichholz et al. [14].

Mitral flow was measured in apical four-chamber view by pulsed Doppler. The sample was positioned between the distal ends of the mitral valve leaflets, and then the following variables were obtained: early $(\mathrm{E})$ and late (A) transmitral diastolic velocities, E/A ratio. Tissue Doppler was performed in the apical four-chamber view to obtain the velocities of the mitral annulus. The sample was placed at the junction of the LV lateral wall 
with the mitral annulus [15], and then early (e') diastolic velocities of the mitral annulus were identified, as well as the $\mathrm{E} / \mathrm{e}^{\prime}$ ratio.

LV dilatation was defined when the LVEDD was $>59 \mathrm{~mm}$ for men and $>53 \mathrm{~mm}$ for women. Systolic dysfunction was considered when the EF was $<50 \%$. LV diastolic function was classified into four patterns: normal, abnormal relaxation (mild diastolic dysfunction), pseudonormal (moderate diastolic dysfunction) and restrictive (severe diastolic dysfunction). It was considered abnormal relaxation when $\mathrm{E} / \mathrm{A}<1$; restrictive pattern when $\mathrm{E} / \mathrm{A}>2$ and pseudonormal pattern when E/A was $>1$ and $<2$ in association with E/e' $>10$ [16].

\subsection{Clinical and Laboratory Data}

Clinical data, including age, gender, comorbidities and dialysis vintage were obtained from detailed analysis of medical records and interviews with the patient and the attending physician, when necessary. Before performing each Doppler echocardiogram, BP was measured and anthropometric data and ratios were obtained (weight, height, BSA, body mass index), which were measured according to standard procedures and using suitable materials. The body mass index (BMI) was calculated by dividing weight $(\mathrm{kg})$ by squared height $(\mathrm{m})$. The BSA was obtained using the formula of Dubois and Dubois [17]. All biochemical measurements were performed by a single laboratory, located in Hidaka Hospital, and data were collected from patients' charts.

\subsection{Outcomes}

The primary endpoint or CV mortality was defined by death from CV causes (including sudden death, myocardial infarction and cerebrovascular accidents). The secondary outcomes included overall mortality. Outcomes were obtained from monthly review of medical documentation, including medical records and death certificates, as well as communication with the physician and patient's relatives. Patients who underwent kidney transplant or who switched dialysis modality were censored in the study.

\subsection{Statistical Analysis}

Quantitative variables are reported as means \pm SD or median and categorical variables as percentages. For comparison of proportions between groups with and without outcome, we used the Chi-square test and for comparison of quantitative variables, Student's $t$-test for independent samples. To estimate the hazard ratios (HR), we performed univariate analysis using Cox proportional hazards model and then, variables with $\mathrm{p}<0.10$ were included in the multivariate analysis using the same model. Survival curves were constructed using the KaplanMeier method and log-rank test was used to compare survival curves in univariate analysis. The significance level was defined as $\mathrm{p}<0.05$.

\section{Results}

The study population consisted of 83 (70.3\%) men and 35 (29.7\%) women, with a mean age of $62.5 \pm 11.5$ years, ranging from 21 to 76 years. The clinical, biochemical and echocardiographic characteristics of the population are listed in Table 1.

The cause of end-stage renal disease was attributed to chronic glomerulonephritis in 54 cases, diabetic nephropathy in 53 cases, hypertensive nephrosclerosis in 6 cases, polycystic kidney disease in 3 cases and other diseases in 2 cases.

The mean follow-up was $45.7 \pm 13.6$ months and during this period, there were twenty-eight deaths and thirteen cardiovascular deaths. CV diseases accounted for $46.4 \%$ of all deaths. Other causes of deaths were septic shock in five cases, malignancies in three cases, gastrointestinal bleeding in three cases and unknown origin in four cases. The event-free survival rates in one and two years were $96.5 \%$ and $83.0 \%$, respectively.

Figure 1 shows the Kaplan-Meier curves for the occurrence of all-cause deaths in HD patients with $(n=53)$ and without diabetes $(\mathrm{n}=65)$. There was no significant difference between the two groups. Figure 2 shows the survival curves free of CV mortality in the two groups. The event-free survival rate in the diabetic group was significantly lower than that of the non-diabetic group $(p=0.006)$.

Table 2 shows the comparison of clinical and echocardiographic characteristics between groups with and without CV deaths. Patients with CV outcome had a higher prevalence of diabetes, higher values of BMI and serum non-HDL-cholesterol and triglyceride, and lower values of diastolic BP and high values of E/e'. 


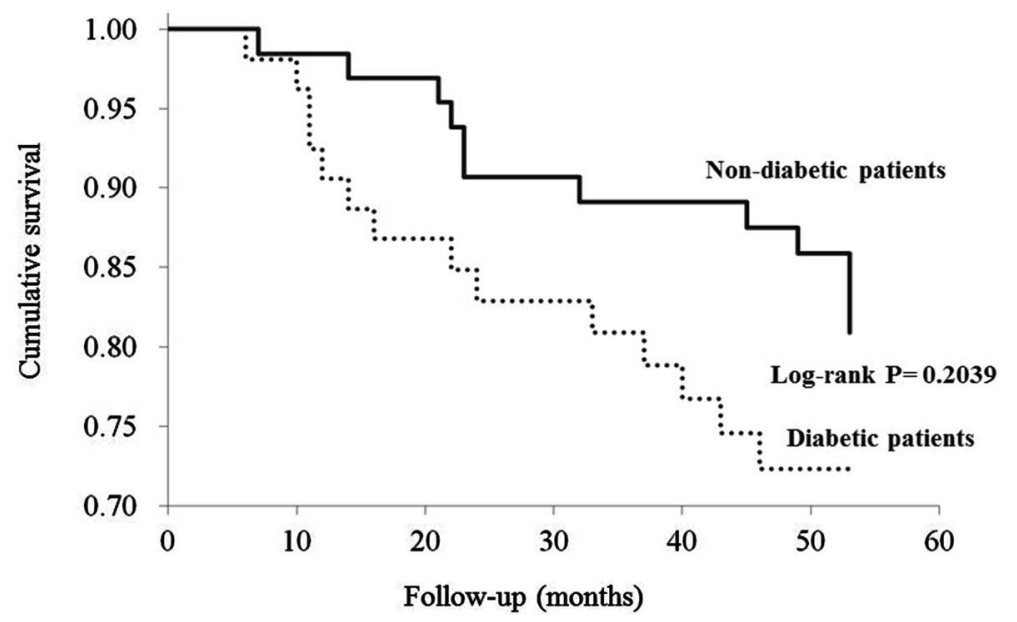

Figure 1. Kaplan-Meier curves for the occurrence of death in HD patients with $(n=53)$ and without diabetes $(n=65)$.

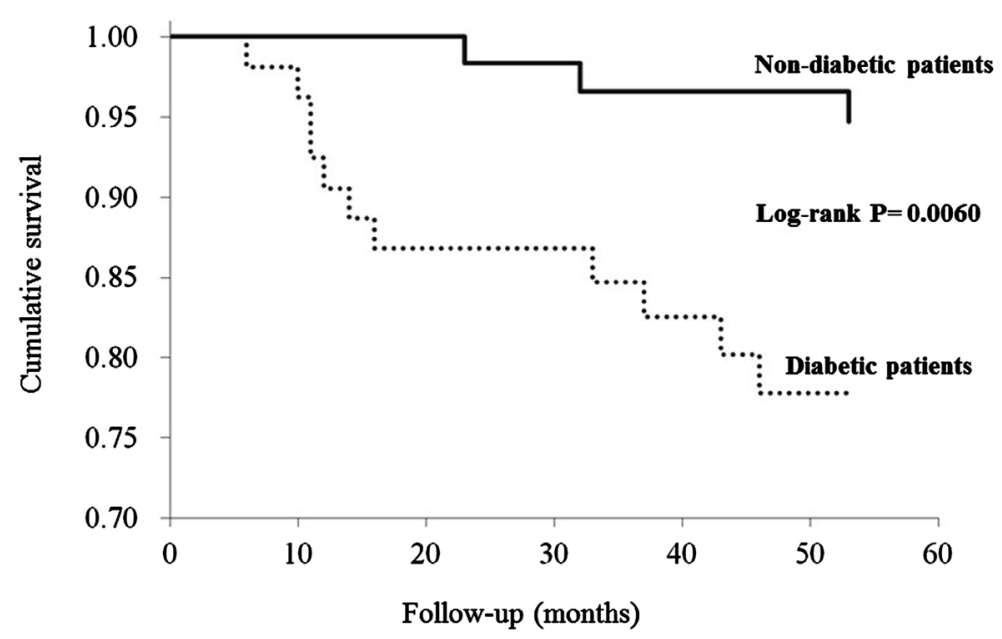

Figure 2. Kaplan-Meier curves for event-free survival from cardiovascular disease in HD patients with $(n=53)$ and without diabetes $(n=65)$.

The univariate Cox model for CV mortality is shown in Table 3. At univariate analysis, dialysis vintage, diabetes mellitus, BMI, serum levels of non-HDL-cholesterol and triglyceride, and E/e' ratio were significantly associated with CV mortality. Multivariate analysis included variables: dialysis vintage, diabetes, systolic and diastolic BP, BMI, HDL- and non-HDL-cholesterol, triglyceride and E/e' ratio. In the final regression model, dialysis vintage, diabetes, systolic BP and E/e' showed themselves to be independent risk factors for CV mortality (Table 4).

\section{Discussion}

This study showed free survival rates of overall mortality of $94.9 \%$ in one year and $87.2 \%$ in two years. These rates are comparable to those found by Siqueira et al. [18], who found survival rates of $96.5 \%$ and $83.0 \%$ in one and two years, respectively. Data from dialysis censuses show survival rates of $88.6 \%$ in one year and $79.1 \%$ in two years in Europe [19] and $77.4 \%$ in one year and 63\% in two years in the USA [1]. The patient characteristics included in this study could explain the differences found. We studied patients without history of previous CV diseases, which is uncommon in this population. Furthermore, the average LVEF was preserved in the subjects studied, characterizing a population of more stable patients from the point of view of LV systolic function.

CVD accounted for $46.4 \%$ of all deaths during follow-up period. The proportion found is similar to those reported in studies on all-cause and CV mortality in HD patients [2] [6]. However, multicenter studies, such as the 
Table 1. Clinical and echocardiographic characteristics of the study population.

\begin{tabular}{|c|c|}
\hline Characteristics & Value $(\mathrm{n}=118)$ \\
\hline Age (years) & $62.5 \pm 11.5$ \\
\hline Male gender (\%) & $83(70.3 \%)$ \\
\hline Dialysis vintage (months) & $79(14-131.4)$ \\
\hline Diabetes (\%) & $53(44.9 \%)$ \\
\hline Systolic BP (mmHg) & $146.3 \pm 17.8$ \\
\hline Diastolic BP (mmHg) & $75.0 \pm 10.4$ \\
\hline $\operatorname{BMI}\left(\mathrm{kg} / \mathrm{m}^{2}\right)$ & $21.6 \pm 3.9$ \\
\hline Albumin (g/dL) & $3.6 \pm 0.3$ \\
\hline Hemoglobin (g/dL) & $10.4 \pm 0.9$ \\
\hline Total cholesterol (mg/dL) & $147.6 \pm 31.0$ \\
\hline HDL cholesterol (mg/dL) & $45.1 \pm 12.0$ \\
\hline Non-HDL cholesterol (mg/dL) & $102.5 \pm 31.6$ \\
\hline Triglyceride (mg/dL) & $112.2 \pm 83.8$ \\
\hline Calcium (mg/dL) & $8.7 \pm 0.6$ \\
\hline Phosphorus (mg/dL) & $5.2 \pm 1.1$ \\
\hline Intact-PTH (pg/mL) & $220.0 \pm 162.5$ \\
\hline LVDD (mm) & $46.9 \pm 5.6$ \\
\hline LVEF (\%) & $66.8 \pm 10.7$ \\
\hline LAD (mm) & $38.5 \pm 6.7$ \\
\hline LVMI $\left(\mathrm{g} / \mathrm{m}^{2}\right)$ & $109.4 \pm 32.5$ \\
\hline $\mathrm{E} / \mathrm{A}$ & $0.8 \pm 0.3$ \\
\hline $\mathrm{E} / \mathrm{e}^{\prime}$ & $15.3 \pm 6.2$ \\
\hline
\end{tabular}

Data are expressed as mean \pm standard deviation, median (range) or percentage. BP, blood pressure; BMI, body mass index; HDL, high-density lipoprotein; PTH, parathyroid hormone; LVDd, left ventricular end-diastolic diameter; EF, ejection fraction; LAD, left atrial diameter; LVMI, left ventricular mass index; E, early diastolic transmitral velocity; A, late diastolic transmitral velocity; e', early diastolic velocity of mitral annulus.

Table 2. Comparison of clinical and echocardiographic characteristics according to the presence of cardiovascular outcome.

\begin{tabular}{|c|c|c|c|}
\hline \multirow{2}{*}{ Characteristics } & \multicolumn{2}{|c|}{ Cardiovascular mortality } & \multirow{2}{*}{ p-value } \\
\hline & No $(n=105)$ & Yes $(n=13)$ & \\
\hline Age (years) & $62.5 \pm 11.4$ & $61.9 \pm 12.7$ & 0.8554 \\
\hline Male sex (\%) & 72.1 & 57.1 & 0.2495 \\
\hline Dialysis vintage (months) & $126.9 \pm 150.6$ & $61.6 \pm 41.2$ & 0.1107 \\
\hline Diabetes (\%) & 40.4 & 78.6 & 0.0070 \\
\hline Systolic BP (mmHg) & $147.4 \pm 16.7$ & $138.2 \pm 24.0$ & 0.0692 \\
\hline Diastolic BP (mmHg) & $75.7 \pm 10.4$ & $69.7 \pm 9.3$ & 0.0431 \\
\hline $\mathrm{BMI}\left(\mathrm{kg} / \mathrm{m}^{2}\right)$ & $21.2 \pm 2.8$ & $24.1 \pm 8.1$ & 0.0084 \\
\hline Albumin (g/dL) & $3.7 \pm 0.3$ & $3.6 \pm 0.3$ & 0.1954 \\
\hline Hemoglobin (g/dL) & $10.4 \pm 1.0$ & $10.4 \pm 0.8$ & 0.8992 \\
\hline Total cholesterol (mg/dL) & $146.0 \pm 30.9$ & $159.7 \pm 30.0$ & 0.1199 \\
\hline HDL cholesterol (mg/dL) & $45.8 \pm 12.0$ & $39.5 \pm 10.9$ & 0.0653 \\
\hline Non-HDL cholesterol (mg/dL) & $100.2 \pm 31.1$ & $120.2 \pm 29.9$ & 0.0249 \\
\hline Triglyceride(mg/dL) & $104.4 \pm 70.1$ & $170.5 \pm 141.7$ & 0.0051 \\
\hline Calcium (mg/dL) & $8.8 \pm 0.7$ & $8.5 \pm 0.5$ & 0.1590 \\
\hline Phosphorus (mg/dL) & $5.2 \pm 1.1$ & $4.8 \pm 0.8$ & 0.1460 \\
\hline Intact-PTH (pg/mL) & $223.2 \pm 168.1$ & $196.4 \pm 115.0$ & 0.5654 \\
\hline LVDD (mm) & $46.8 \pm 5.6$ & $47.8 \pm 5.2$ & 0.5435 \\
\hline LVEF (\%) & $66.8 \pm 9.9$ & $66.4 \pm 15.9$ & 0.8760 \\
\hline $\mathrm{LAD}(\mathrm{mm})$ & $38.2 \pm 5.8$ & $40.4 \pm 11.5$ & 0.2631 \\
\hline LVMI (g/m²) & $108.5 \pm 32.1$ & $116.0 \pm 36.0$ & 0.4200 \\
\hline $\mathrm{E} / \mathrm{A}$ & $0.8 \pm 0.3$ & $0.9 \pm 0.4$ & 0.2024 \\
\hline $\mathrm{E} / \mathrm{e}^{\prime}$ & $14.9 \pm 5.3$ & $18.6 \pm 10.0$ & 0.0317 \\
\hline
\end{tabular}


Table 3. Predictors of cardiovascular mortality by univariate analysis of Cox regression model.

\begin{tabular}{|c|c|c|c|}
\hline Characteristics & HR & $95 \%$ CI & $\mathrm{p}$ \\
\hline Age (years) & 0.995 & $0.954-1.043$ & 0.8144 \\
\hline Male sex (\%) & 0.555 & $0.193-1.687$ & 0.2862 \\
\hline Dialysis vintage (months) & 0.990 & $0.978-0.998$ & 0.0152 \\
\hline Diabetes (\%) & 5.017 & $1.565-22.193$ & 0.0055 \\
\hline Systolic BP (mmHg) & 0.974 & $0.945-1.004$ & 0.0830 \\
\hline Diastolic BP (mmHg) & 0.963 & $0.933-1.005$ & 0.0791 \\
\hline $\operatorname{BMI}\left(\mathrm{kg} / \mathrm{m}^{2}\right)$ & 1.142 & $1.030-1.237$ & 0.0147 \\
\hline Albumin (g/dL) & 0.234 & $0.034-1.698$ & 0.1506 \\
\hline Hemoglobin $(\mathrm{g} / \mathrm{dL})$ & 1.038 & $0.578-1.710$ & 0.8918 \\
\hline Total cholesterol (mg/dL) & 1.012 & $0.996-1.028$ & 0.1318 \\
\hline HDL cholesterol (mg/dL) & 0.956 & $0.911-1.001$ & 0.0533 \\
\hline Non-HDL cholesterol (mg/dL) & 1.018 & $1.002-1.033$ & 0.0289 \\
\hline Triglyceride(mg/dL) & 1.006 & $1.002-1.009$ & 0.0111 \\
\hline Calcium (mg/dL) & 0.583 & $0.264-1.284$ & 0.1796 \\
\hline Phosphorus (mg/dL) & 0.676 & $0.374-1.151$ & 0.1556 \\
\hline Intact-PTH $(\mathrm{pg} / \mathrm{mL})$ & 0.999 & $0.994-1.002$ & 0.6106 \\
\hline LVDD (mm) & 1.033 & $0.939-1.132$ & 0.4979 \\
\hline LVEF (\%) & 0.992 & $0.945-1.047$ & 0.7541 \\
\hline LAD (mm) & 1.054 & $0.970-1.141$ & 0.2118 \\
\hline LVMI $\left(\mathrm{g} / \mathrm{m}^{2}\right)$ & 1.006 & $0.991-1.021$ & 0.4082 \\
\hline $\mathrm{E} / \mathrm{A}$ & 2.911 & $0.531-12.011$ & 0.2005 \\
\hline $\mathrm{E} / \mathrm{e}^{\prime}$ & 1.092 & $1.009-1.172$ & 0.0301 \\
\hline
\end{tabular}

Table 4. Predictors of cardiovascular mortality by multivariate analysis of Cox regression model.

\begin{tabular}{cccc}
\hline Characteristics & HR & $95 \%$ CI & p \\
\hline Dialysis vintage (months) & 0.989 & $0.975-0.999$ & 0.0187 \\
Diabetes (\%) & 7.230 & $1.553-45.036$ & 0.0107 \\
Systolic BP (mmHg) & 0.956 & $0.898-0.997$ & 0.0368 \\
Diastolic BP (mmHg) & 0.951 & $0.889-1.074$ & 0.3375 \\
BMI $\left(\mathrm{kg} / \mathrm{m}^{2}\right)$ & 1.056 & $0.934-1.181$ & 0.3591 \\
HDL cholesterol (mg/dL) & 0.961 & $0.901-1.020$ & 0.1976 \\
Non-HDL cholesterol (mg/dL) & 1.023 & $0.998-1.051$ & 0.0768 \\
Triglyceride(mg/dL) & 0.999 & $0.991-1.005$ & 0.7132 \\
E/e' & 1.100 & $1.011-1.202$ & 0.0267 \\
\hline
\end{tabular}

HEMO and AURORA studies, showed rates of less than 50\% of mortality due to CV disease in the dialysis population [19] [20]. These results confirm that CV diseases remain the leading cause of mortality in HD patients. HD patients have a 10 - 20-fold higher risk of CV mortality compared with the general population [21] and this is due to the fact that HD patients are exposed to both traditional as well as non-traditional factors for CV complications [22].

The results of this study suggested that diabetes is related to a higher risk of CV mortality, as previously described [23]. CV disease in diabetic patients is usually attributed to coronary artery disease resulting from an accelerated process of atherosclerosis [24]. Diabetic patients are also more prone to develop congestive heart failure, independently of the presence of coronary artery disease or hypertension [25]. This is probably due to the presence of diabetic cardiomyopathy; there is substantial experimental, pathological, epidemiological, and clinical evidence to support the existence of specific abnormalities in cardiac structure and function in diabetic patients [26].

We have shown that LV diastolic dysfunction is associated with higher CV mortality of HD patients in this study. Nardi et al. evaluated how diabetes affected LV geometry and diastolic function in 288 hypertensive patients with chronic kidney disease [27]. They found that diabetes together with renal dysfunction was associated with a worse diastolic function with significantly higher E/e'. Hung et al. have recently showed that diabetic HD patients had a more profound LV diastolic dysfunction, as estimated E/e' [28]. The mechanisms and evolution of 
diastolic dysfunction are not completely understood, especially in diabetic patients. Several factors affect LV function and transmitral flow: preload, after load, heart rate, LV mass, metabolic and hormonal parameters, myocardial innervation, and microangiopathic lesions [29]. The increased proportion of diabetic patients with moderate or severe LV diastolic dysfunction was not related to the presence of myocardial ischemia or hypertension, because the frequency of these factors was not higher in diabetic HD patients [30].

LV diastolic dysfunction combines relaxation and compliance abnormalities. As a result of poor compliance, a slight increase in preload can induce a sharp increase in LV pressure, leading to congestion. On the other hand, a small increase in filling pressure can reduce systolic ejection volume and cardiac output. These abnormalities might predispose diabetic HD patients to hemodynamic instability and hypotension [31]. Myocardial fibrosis resulting from these processes is a major determinant of LV stiffness and elevated filling pressures, predisposing to the development of LV diastolic dysfunction [32]. In a recently published study, which evaluated $211 \mathrm{HD}$ patients and used conventional Doppler and tissue Doppler criteria to classify diastolic dysfunction, Quiroqa et al. [33] have shown that LV diastolic dysfunction is an emergent risk factor for death and CV events in HD patients.

The present study has several limitations. First, the number of patients studied was small and highly selective. Most of the patients in this study had normal LVEF despite six patients that had LVEF below 50\%. Patients with normal LVEF without structural heart diseases are difficult to identify, especially HD patients. Additionally, Doppler techniques are highly dependent on investigator. In this study, echocardiographic parameters were recorded by a specialist according to the guideline of American society of Echocardiography. However, this technique allows periodic analysis in patients who have high rates of CV events.

\section{Conclusion}

Chronic HD patients have high rates of CV mortality. The presence of diabetes and high E/e' are factors potentially related to CV mortality. LV diastolic dysfunction was an independent risk factor for CV mortality, and although further studies are necessary to validate this finding, it is recommended that LV diastolic function evaluation, made through pulsed Doppler and tissue Doppler parameters, included in the evaluation of HD patients. This measure will enable the early detection of HD patients at risk in order to reduce mortality.

\section{Acknowledgements}

We thank medical staffs for dialysis center in the Hidaka Hospital for collecting medical records. This work was supported by grants from the Japan Research Promotion Society for Cardiovascular Diseases.

\section{Conflict of Interest}

The authors have declared that no conflict of interest exists.

\section{References}

[1] United States Data System. 2010 Annual Data Report. Atlas of Chronic Kidney Disease and End-Stage Renal Disease in the United States. Bethesda, MD: National Institutes of Health, National Institute of Diabetes and Digestive and Kidney Diseases; 2010.

[2] Nakai, S., Watanabe, Y., Masakane, I., Wada, A., Shoji, T. Hasegawa, T., et al. (2013) Overview of Regular Dialysis Treatment in Japan (as of 31 December 2011). Therapeutic Apheresis and Dialysis, 17, 567-611. http://dx.doi.org/10.1111/1744-9987.12147

[3] Parfrey, P.S. and Foley, R.N. (1999) The Clinical Epidemiology of Cardiac Disease in Chronic Renal Failure. Journal of American Society of Nephrology, 10, 1606-1615.

[4] Fujiu, A., Ogawa, T., Matsuda, N., Ando, Y. and Nitta, K. (2008) Aortic Arch Calcification and Arterial Stiffness Are Independent Factors for Diastolic Left Ventericular Dysfunction in Chronic Hemodialysis Patients. Circulation Journal, 72, 1768-1772. http://dx.doi.org/10.1253/circj.CJ-08-0308

[5] Yamazaki, M., Ogawa, T., Tamei, N., Ando, Y. and Nitta, K. (2011) Relation of N-Terminal pro-B-Type Natriuretic Peptide (NT-proBNP) and Left Atrial Volume Index to Left Ventricular Function in Chronic Hemodialysis Patients. Heart Vessels, 26, 421-427. http://dx.doi.org/10.1007/s00380-010-0066-4

[6] London, G.M., Pannier, B., Guerin, A.P., Blacher, J., Marchais, S.J., Darne, B., et al. (2001) Alterations of Left Ventricular Hypertrophy in and Survival of Patients Receiving Hemodialysis: Follow-Up of An Interventional Study. 
Journal of American Society of Nephrology, 12, 2759-2767.

[7] Zoccali, C., Benedetto, F.A., Mallamaci, F., Tripepi, G., Giacone, G., Cataliotti, A., et al. (2004) Prognostic Value of Echocardiographic Indicators of Left Ventricular Systolic Function in Asymptomatic Dialysis Patients. Journal of American Society of Nephrology, 15, 1029-1037. http://dx.doi.org/10.1097/01.ASN.0000117977.14912.91

[8] Chen, S.C., Chang, J.M., Liu, W.C., Huang, J.C., Tsai, J.C., Lin, M.Y., et al. (2012) Echocardiographic Parameters Are Independently Associated with Increased Cardiovascular Events in Patients with Chronic Kidney Disease. Nephrology Dialysis Transplantation, 27, 1064-1070. http://dx.doi.org/10.1093/ndt/gfr407

[9] Iwabuchi, Y. Ogawa, T., Inoue T, Otsuka, K., Nitta, K. (2012) Elevated E/E' Predicts Cardiovascular Events in Hemodialysis Patients with Preserved Systolic Function. Internal Medicine, 51, 155-160. http://dx.doi.org/10.2169/internalmedicine.51.6250

[10] Schiller, N.B., Shah, P.M., Crawford, M., DeMaria, A., Devereux, R., Feigenbaum, H., et al. (1989) Recommendations for Quantitation of the Left Ventricle by Two-Dimensional Echocardiography. American Society of Echocardiography Committee on Standards, Subcommittee on Quantitation of Two-Dimensional Echocardiograms. Journal of American Society of Echocardiography, 2, 358-367.

[11] Quiñones, M.A., Otto, C.M., Stoddard, M., Waggoner, A. and Zoghbi, W.A. (2002) Recommendations for Quantification of Doppler Echocardiography: A Report from the Doppler Quantification Task Force of the Nomenclature and Standards Committee of the American Society of Echocardiography. Journal of American Society of Echocardiograpy, 15, 167-184. http://dx.doi.org/10.1067/mje.2002.120202

[12] Nagueh, S.F., Appleton, C.P., Gillebert, T.C., Marino, P.N., Oh, J.K., Smiseth, O.A., et al. (2009) Recommendations for the Evaluation of Left Ventricular Diastolic Function by Echocardiography. Journal of American Society of Echocardiography, 22, 107-133. http://dx.doi.org/10.1016/j.echo.2008.11.023

[13] Devereux, R.B., Alonso, D.R., Lutas, E.M., Gottlieb, G.J., Campo, E., Sachs, I., et al. (1986) Echocardiographic Assessment of Left Ventricular Hypertrophy: Comparison to Necropsy Findings. American Journal of Cardiology, 57, 450-458. http://dx.doi.org/10.1016/0002-9149(86)90771-X

[14] Teichholz, L.E., Kreulen, T., Herman, M.V. and Gorlin, R. (1976) Problems in Echocardiographic Volume Determinations: Echocardiographic-Angiographic Correlations in the Presence or Absence of Asynergy. American Journal of Cardiology, 37, 7-11. http://dx.doi.org/10.1016/0002-9149(76)90491-4

[15] Kasner, M., Westermann, D., Steendijk, P., Gaub, R., Wilkenshoff, U., Weitmann, K., et al. (2007) Utility of Doppler Echocardiography and Tissue Doppler Imaging in the Estimation of Diastolic Function in Heart Failure with Normal Ejection Fraction: A Comparative Doppler-Conductance Catheterization Study. Circulation, 116, 637-647. http://dx.doi.org/10.1161/CIRCULATIONAHA.106.661983

[16] Khouri, S.J., Maly, G.T., Suh, D.D. and Walsh, T.E. (2004) A Practical Approach to the Echocardiographic Evaluation of Diastolic Function. Journal of the American Society of Echocardiograpy, 17, 290-297. http://dx.doi.org/10.1016/j.echo.2003.08.012

[17] Dubois, D. and Dubois, E.F. (1916) A Formula to Estimate the Approximate Surface Area If Height and Weight be Known. JAMA Internal Medicine, 17, 863-871. http://dx.doi.org/10.1001/archinte.1916.00080130010002

[18] Siqueira, T.M., Ferreira, P.A., das Chagas Monteiro Junior, F., Salqado Fiho, N., Ferreira Ade, S., Santos Neto, E.D., et al. (2012) Echocardiographic Parameters as Cardiovascular Event Predictors in Hemodialysis Patients. Arquivos Brasileiros de Cardiologia, 99, 714-723. http://dx.doi.org/10.1590/S0066-782X2012005000065

[19] Cheung, A.K., Sarnak, M.J., Yan, G., Berkoben, M., Heyka, R., Kaufman, A., et al. (2004) Cardiac Diseases in Maintenance Hemodialysis Patients: Results of the HEMO Study. Kidney International, 65, 2380-2389. http://dx.doi.org/10.1111/j.1523-1755.2004.00657.x

[20] Fellström, B.C., Jardine, A.G., Schmieder, R.E., Holdaas, H., Bannister, K., Beutler, J., et al. (2009) Rosuvastatin and Cardiovascular Events in Patients Undergoing Hemodialysis. New England Journal of Medicine, 360, 1395-1407. http://dx.doi.org/10.1056/NEJMoa0810177

[21] Foley, R.N., Parfrey, P.S. and Sarnak, M.J. (1998) Clinical Epidemiology of Cardiovascular Disease in Chronic Renal Disease. American Journal of Kidney Diseases, 32, S112-S119. http://dx.doi.org/10.1053/ajkd.1998.v32.pm9820470

[22] Zoccali, C., Mallamaci, F. and Tripepi, G. (2004) Novel Cardiovascular Risk Factors in End-Stage Renal Disease. Journal of the American Society of Nephrology, 15, S77-S80. http://dx.doi.org/10.1097/01.ASN.0000093240.84097.FE

[23] Foley, R.N., Culleton, B.F., Parfrey, P.S., Harnett, J.D., Kent, G.M., Murray, D.C., et al. (1997) Cardiac Disease in Diabetic End-Stage Renal Disease. Diabetologia, 40, 1307-1312. http://dx.doi.org/10.1007/s001250050825

[24] Burchfiel, C.M., Reed, D.M., Marcus, E.B., Strong, J.P. and Hayashi, T. (1993) Association of Diabetes Mellitus with Coronary Atherosclerosis and Myocardial Lesions. An Autopsy Study from the Honolulu Heart Program. American Journal of Epidemiology, 137, 1328-1340.

[25] Kannel, W.B., Hjortland, M. and Castelli, W.P. (1974) Role of Diabetes in Congestive Heart Failure: The Framingham 
Study. American Journal of Cardiology, 34, 29-34. http://dx.doi.org/10.1016/0002-9149(74)90089-7

[26] Galderisi, M., Anderson, K.M., Wilson, P.W. and Levy, D. (1991) Echocardiographic Evidence for the Existence of a Distinct Diabetic Cradiomyopathy (The Framingham Heart Study). American Journal of Cardiology, 68, 85-89. http://dx.doi.org/10.1016/0002-9149(91)90716-X

[27] Nardi, E., Palermo, A., Mule, G., Cusimano, P., Cottone, S. and Cerasola, G. (2011) Impact of Type 2 Diabetes on Left Ventricular Geometry and Diastolic Function in Hypertensive Patients with Chronic Kidney Disease. Journal of Human Hypertension, 25, 144-151. http://dx.doi.org/10.1038/jhh.2010.96

[28] Hung, K.C., Lee, C.H., Chen, C.C., Chu, C.M., Wang, C.Y., Hsieh, I.C., et al. (2012) Advanced Left Ventricular Diastolic Dysfunction in Uremic Patients with Type 2 Diabetes on Maintenance Hemodialysis. Circulation Journal, 76, 2380-2385. http://dx.doi.org/10.1253/circj.CJ-12-0471

[29] Kunz, K., Dimitrov, Y., Muller, S., Chantrel, F. and Hannedouche, T. (1998) Uraemic Cardiomyopathy. Nephrology Dialysis Transplantation, 13, 39-43.

[30] Zaslavsky, L.M., Pinotti, A.F. and Gross, J.L. (2005) Diastolic Dysfunction and Mortality in Diabetic Patients on Hemodilaysis: A 4.25-Year Controlled Prospective Study. Journal of Diabetes and Its Complications, 19, $194-200$. http://dx.doi.org/10.1016/j.jdiacomp.2004.12.001

[31] Herzog, C.A., Asinger, R.W., Berger, A.K., Charytan, D.M., Díez, J., Hart, R.G., et al. (2011) Cardiovascular Disease in Chronic Kidney Disease. A Clinical Update from Kidney Disease: Improving Global Outcomes (KDIGO). Kidney International, 80, 572-586. http://dx.doi.org/10.1038/ki.2011.223

[32] Pcoits-Filho, R., Bucharles, S. and Barberato, S.H. (2012) Diastolic Heart Failure in Dialysis Patients: Mechanisms, Diagnostic Approach, and Treatment. Seminars in Dialysis, 25, 35-41. http://dx.doi.org/10.1111/j.1525-139X.2011.01011.x

[33] Quiroga, B., Villaberde, M., Abad, S., Vega, A., Reque, J. and Lopez-Gomez, J.M. (2013) Diastolic Dysfunction and High Levels of New Cardiac Biomarkers as Risk Factors for Cardiovascular Events and Mortality in Hemodialysis Patients. Blood Purification, 36, 98-106. http://dx.doi.org/10.1159/000354080 
Scientific Research Publishing (SCIRP) is one of the largest Open Access journal publishers. It is currently publishing more than 200 open access, online, peer-reviewed journals covering a wide range of academic disciplines. SCIRP serves the worldwide academic communities and contributes to the progress and application of science with its publication.

Other selected journals from SCIRP are listed as below. Submit your manuscript to us via either submit@scirp.org or Online Submission Portal.
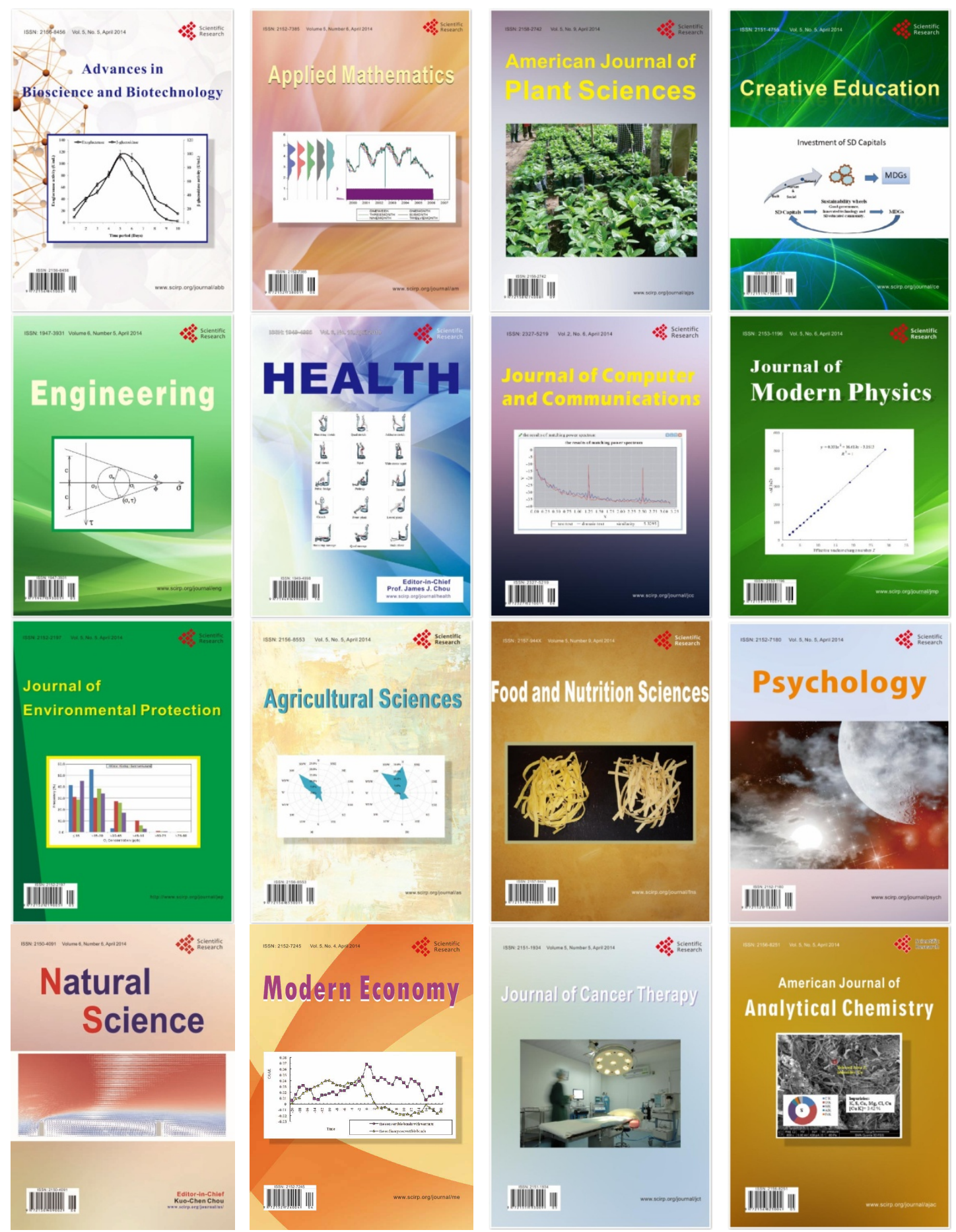